\section{Periodontal Condition and Immunological Aspects of Individuals Hospitalized in the Intensive Care Unit}

Bárbara Nascimento Albuquerque1, Milena Moreira Araújo ${ }^{1}$, Tarcília Aparecida Silva1', Luís Otávio Miranda Cota ${ }^{1}$, Sheila Cavalca Cortelli1,2, Fernando Oliveira Costa ${ }^{1}$
'UFMG - Universidade

Federal de Minas Gerais, Belo

Horizonte, MG, Brazil

2UNITAU - Universidade de

Taubaté, Taubaté, SP, Brazil

Correspondence: Fernando Oliveira Costa, Avenida Antonio Carlos, 6627, 31270-901 Belo Horizonte, MG, Brasil. Tel: +55-31-3499-2412. e-mail: focperio@uol.com.br
There are few studies on the clinical and immunological periodontal status of intensive care unit (ICU) in-patients. The aim of the present study was to evaluate the periodontal condition among ICU in-patients through clinical and immunological periodontal parameters. From the sample of 373 hospitalized ICU patients, 182 were submitted' to a thorough clinical periodontal and immunological evaluation. Data on bleeding on probing (BOP), probing depth (PD), and clinical attachment level (CAL) were collected and gingival sulcular fluid samples were quantified through ELISA on IL-1, IL-6, and MMP-2 for immunological evaluation. Data was statistically analyzed by Chi-square, Fisher's exact, Mann-Whitney tests, and Sperman's correlation and multivariate logistic regression analysis. A high dental plaque index and a high prevalence of periodontitis (48.3\%), mostly in moderate and localized chronic form, were observed. Individuals with periodontitis presented higher levels of IL-1 and MMP-2, while individuals with cardiovascular disease (CVD) and individuals with two or more systemic diseases (MSD) presented higher levels of IL-1; diabetes mellitus (DM) and MSD individuals presented higher levels of IL-6. A positive association was found between the severity of periodontitis and CVD (OR 2.2; $\mathrm{Cl}=1.11-4.42)$. This study reported a $48.3 \%$ of the prevalence of periodontitis in ICU patients and a positive association between the severity of periodontitis and CVD. Additionally, higher levels of IL-1 and MMP-2 were found in individuals with periodontitis, higher levels of IL-6 were found in individuals with DM, and higher levels of IL-1 were found in individuals with CVD.
Key Words: periodontal disease, periodontitis, hospitalization, cytokines.

\section{Introduction}

Periodontitis is a chronic infectious inflammatory multifactorial disease characterized by progressive destruction of the tissues supporting the teeth, and its evolution can lead to tooth loss. Periodontitis accounts for a substantial proportion of tooth loss, with impacts on dental costs and health general (1).

This process is caused by oral anaerobic and facultative microorganisms that release primarily proteolytic enzymes (1) with high virulence, the lipopolysaccharide (LPS) of gram-negative bacteria results in the induced expression of pro-inflammatory agents such as interleukin (IL) -1, IL$1 \beta$, IL-6, tumor necrosis factor, prostaglandins, and matrix metalloproteinases (MMPs) that may contribute to trigger the destruction of periodontal tissues (2-4). Additionally, the same biomarkers have been associated with several chronic systemic diseases (5).

Periodontitis can significantly increase the risk or alter the natural course of certain systemic chronic diseases (5). Studies have inquired about a possible association between periodontitis and several different diseases, including diabetes mellitus (DM), cardiovascular diseases (CVD), and respiratory diseases (RD) (5).

Pre-existing periodontal conditions in hospitalized individuals has been associated with increased severity of other associated co-morbidities, especially respiratory and cardiovascular diseases (6-8). It is noteworthy that, respiratory and cardiovascular diseases determine $~ 50 \%$ of the reasons for hospitalization in ICU, when cases of poly-traumas and sepsis are not considered.

Studies show that the oral health of individuals can deteriorate after short periods of hospitalization, as indicated by the increase in dental plaque and gingival inflammation (8). Pathogens in biofilm have also been implicated in inflammatory processes that can compromise the function of organs and systems, thereby contributing to increased morbidity and mortality and higher costs associated with care health (6).

In the ICU environment, individuals experience greater systemic vulnerability, as well as a possible worsening of oral conditions (2), which may contribute to infectious complications in clinical outcome that compromise the quality of care.

Our hypothesis is that individuals in the ICU with periodontitis or worse periodontal conditions would demonstrate higher levels of IL-1, IL-6, and MMP-2 with potential risk to systemic health.

At present, few studies have evaluated the periodontal 
condition from a clinical and particularly immunological perspective in Intensive Care Unit (ICU) in-patients (6-8). Consequently, this study aimed to evaluate the periodontal condition among ICU in-patients through clinical and immunological periodontal parameters.

\section{Material and Methods}

\section{Study Sample and Sampling Strategy}

In the present cross-sectional study, conducted between March 2013 and December 2015, 373 individuals of both genders, between 30 and 82 years of age, were evaluated during their stay at the São Francisco de Assis Hospital's ICU, in Belo Horizonte, Brazil. This study was approved by the Ethics Committee (protocols \# 14943614.8.0000.5149 and \# 42197115.7.0000.5120). All procedures were performed in accordance with the appropriate institutional review body and carried out with the ethical standards set forth in the Helsinki Declaration of 1975.

From the initial sample of 373 hospitalized ICU patients, anyone meeting the following criteria were excluded: (a) age $<30$ years old $(n=22)$; (b) use of antibiotics or antiinflammatory drugs currently or in the previous three $\therefore$ months $(n=45) ;(c)$ presenting with less than six natural teeth $(n=53)$; (d) intubated ( $n=39)$; (e) sedated $(n=4)$; (f) polytrauma-based ICU admission $(n=6)$; $(\mathrm{g})$ general postoperative surgery with no associated cardiovascular or respiratory diseases or complications due to diabetes mellitus ( $n=18) ;(h)$ not mentally fit to answer health questions (with no guardians); (i) lack of information on diseases of interest $(n=4)$. Therefore, the final sample was composed of 182 participants.

The individuals or accompanying persons answered questions about medical and dental history and gave information about social, demographic, and behavioral risk variables for periodontitis; they also completed a periodontal clinical examination and immunological sampling.

\section{Sample Characterization}

The following data were collected through medical records and personal interviews: gender, age, co-housing status, family income, schooling (more/less than 12 years), usage of antibiotic or anti-inflammatory drugs in the last three months, chronic medication, presence of associated illnesses or systemic diseases, especially DM, CVD, and RD, smoking status (smoker, non-smoker, or former smoker) according to Tomar and Asma (9), alcohol intake (nonalcoholic: no intake or casual intake, with a minimum of two days between intakes; alcoholic: daily intake regardless of amount or kind of liquor; and ex-alcoholic: currently no intake, regardless of time, but previously alcoholic), history of periodontitis, previous periodontal treatment, frequency of brushing, flossing (yes/no), and the reason for and expected length of ICU admission.

\section{Diagnosis, Extension, and Severity of Periodontitis}

The criteria for periodontitis case definition were the presence of at least four teeth with a minimum $\geq 4 \mathrm{~mm}$ probing depth (PD) and a $\geq 3 \mathrm{~mm}$ clinical attachment level (CAL) on the same site (10). Severity of periodontitis was defined as (a) mild-to-moderate - CAL between 3-4 mm, and severe - $C A L \geq 5 \mathrm{~mm}$ (1). Extension of periodontitis was defined as (a) localized - up to 30\% of affected sites and (b) generalized - over $30 \%$ of sites affected with CAL $>3 \mathrm{~mm}$ (1).

\section{Clinical Periodontal Examination}

Initially, oral hygiene level of each sextant was determined by means of the plaque index (PI) using disclosing agents. The Quigley \& Hein Pl, modified by Turesky et al. (11), was used for this purpose. In all examinations, the HuFriedy ${ }^{\circledR}$ periodontal probe (UNS-15, Hu-Friedy, Chicago, IL, USA.) was used together with a clinical mirror and gauze. For the four periodontal sites (distal, vestibular, mesial, lingual/palatal), the following data were registered: (a) probing depth (PD), (b) clinical attachment level (CAL) and (c) bleeding on probing (BOP). BOP was assessed when the probing measurements were taken and recorded within a 15-s time interval in a dichotomized manner (presence/ absence) at four sites per tooth (buccal, distal, mesial and lingual). The methodology for periodontal examination was fully described by Lorentz et al. (12).

Examinations and interviews were carried out by two trained professionals and periodontal experts (BNA and MMA). A Kappa inter- and intra-examiner concordance test was performed in a pilot study with 12 individuals for PD and $C A L$, which resulted in over 0.87 . An intraclass correlation test resulted in over 0.89 .

\section{Immunological Analysis Sampling}

Samples from the gingival sulcular fluid on the four sites with the highest PD were collected, containing a sample from the four buccal quadrants whenever possible. The gingival crevicular fluid samples on the Periopaper (Oraflow, FL, USA) were measured using a calibrated Periotron (Periotron 8000 ${ }^{\circledR}$ model 400-8000; Oraflow, FL, USA). Concentrations of IL-1, IL-6, and MMP-2 were measured through enzymelinked immunosorbent assay (ELISA) and processed according to the manufacturer's instructions ( $(R$ \& $D$ Systems' Kit, Minneapolis, MN, USA). Results were presented in cytokine picograms. The collection and processing methodology and detailed definitions of these cytokines are the same as those reported in a previous study (13).

\section{Statistical Analysis}

Comparisons between the prevalence, severity, and 
extension of periodontitis and the quantitative variables of interest were performed by a non-parametric MannWhitney test. Analysis between periodontitis occurrence and the categorical risk variables were performed by the X2 or Fisher's exact test. Additionally, the effect of independent variables on the occurrence of periodontitis cases was evaluated through a multivariate logistic regression analysis. Different models, with and without periodontal variables, were created. Therefore, all of the corresponding variables for each model were selected for the logistic regression $(p<0.25)$ and ruled out if significant $p$ values $(p<0.05)$ were obtained. First-order interactions between alcoholism and CVD were tested and kept if significant. All results were analyzed on SPSS 17.0 (Statistical Package for Social Sciences, Version for Windows - SPSS Inc., Chicago, IL, USA.).

\section{Results}

Of the 182 ICU in-patients sampled in this study, 69 were female and 113 were male and the mean age was 56.3 $( \pm 17.4)$ years. The average length of stay was \pm 6.6 days.

The periodontal condition of the sample is show in Table 1. It features an average percentage of sites with CAL $\geq 3 \mathrm{~mm}$ in $68.6 \%$ of the sample, PD $\geq 4 \mathrm{~mm}$ in $16.1 \%$, and higher \% of sites with BOP (31.3\%). Additionally, a high PI was observed in this population (percentage of teeth with plaque of patients with periodontitis: $67.8 \%( \pm 18.3)$ and without periodontitis: $55.5 \%( \pm 13.5)$; $[p=0.041])$.

The prevalence of periodontitis was $48.3 \%$ in the studied

Table 1. Periodontal condition of the sample $(n=182)$

\begin{tabular}{|c|c|c|}
\hline Periodontal clinical parameters & \multicolumn{2}{|c|}{ Mean \pm sd } \\
\hline Sites with BOP (\%) & \multicolumn{2}{|c|}{$31.3 \pm 29.1$} \\
\hline Teeth with BOP (\%) & \multicolumn{2}{|c|}{$13.3 \pm 16.5$} \\
\hline Sites with PD $<4$ mm (\%) & \multicolumn{2}{|c|}{$83.9 \pm 18.0$} \\
\hline Sites with PD 4 to $6 \mathrm{~mm}(\%)$ & \multicolumn{2}{|c|}{$13.9 \pm 14.3$} \\
\hline Sites with PD > 6 mm (\%) & \multicolumn{2}{|c|}{ 2. $2 \pm 6.0$} \\
\hline Sites with $\mathrm{CAL}<3 \mathrm{~mm}(\%)$ & \multicolumn{2}{|c|}{$31.4 \pm 22.7$} \\
\hline Sites with CAL $\geq 3 \mathrm{~mm}(\%)$ & \multicolumn{2}{|c|}{$68.6 \pm 22.2$} \\
\hline Sites with CAL $\geq 5 \mathrm{~mm}(\%)$ & \multicolumn{2}{|c|}{$19.7 \pm 21.3$} \\
\hline \multirow{4}{*}{$\begin{array}{l}\text { Chronic periodontitis } \\
(n=88 ; 48.3 \%)\end{array}$} & \multicolumn{2}{|c|}{ Severity } \\
\hline & $\begin{array}{l}\text { Mild to Moderate } \\
n=45(51.1 \%)\end{array}$ & $\begin{array}{c}\text { Severe } \\
n=43(48.9 \%)\end{array}$ \\
\hline & \multicolumn{2}{|c|}{ Extension } \\
\hline & $\begin{array}{c}\text { Localized } \\
n=63(71.6 \%)\end{array}$ & $\begin{array}{c}\text { Generalized } \\
\mathrm{n}=25(28.4 \%)\end{array}$ \\
\hline
\end{tabular}

$\mathrm{BOP}=$ bleeding on probing; $\mathrm{PD}=$ probing depth; $\mathrm{CAL}=$ clinical attachment level; $s d=$ standard deviation. population. In the group with periodontitis $(n=88), 51.1 \%$ presented mild to moderate chronic periodontitis $(n=45)$ and $48.9 \%$ presented severe chronic periodontitis $(n=43)$. Meanwhile, $71.6 \%$ of the patients with periodontitis presented the localized form, while $28.4 \%$ presented the generalized form (Table 1).

The prevalence of periodontitis in individuals with CVD, $\mathrm{RD}, \mathrm{DM}$, and with two or more concomitant systemic disease (MSD) was $53.2 \% ; 31.6 \% ; 48.2 \%$ and $42.3 \%$, respectively (Table 2). The present study found a positive association between periodontitis case and the occurrence of CVD in the univariate analysis $(p=0.048 ; O R=1.86 ; 95 \% \mathrm{Cl} 1.08-3.52)$, however with no significance when considering the severity and the extension of periodontitis. Through the univariate analysis, no significant results were found between the occurrence, the severity, and the extension of periodontitis and RD, DM or MSD in the studied sample (Table 2).

Table 3 shows that individuals with CVD presented a significantly higher percentage of BOP sites ( $p=0.043)$, PD $\geq 4 \mathrm{~mm}(p=0.020)$ and $\geq 6 \mathrm{~mm}(p=0.017)$ than individuals without CVD. RD presented a significant higher percentage of sites with a $P D \geq 6 \mathrm{~mm}$ ( $p=0.023)$.

Regarding the immunological analysis, when comparing the occurrence, severity, and extension of periodontitis with levels of IL-1, IL-6, and MMP-2, individuals with periodontitis presented significantly higher levels of IL-1 $(\mathrm{p}<0.001)$ and MMP-2 $(\mathrm{p}=0.025)$ than individuals without periodontitis. Additionally, significant associations for all levels of cytokines were reported when individuals with severe and generalized periodontitis were compared to individuals without periodontitis (Table 4).

Additionally, levels of IL-1, IL-6, and MMP-2 were not significantly associated with the occurrence of $\mathrm{RD}$, although significant results with higher levels of IL-1 were reported for CVD ( $p=0.029)$ and MSD $(p=0.042)$. Regarding IL-6 significant results for DM $(p=0.002)$ and MSD ( $p=0.03)$ (Table 5).

In Table 6, an initial and final model of logistic regression is presented to identify periodontitis case associated factors. Alcoholism $(\mathrm{OR}=2.42$; $95 \% \mathrm{Cl} 1.25-4.68 ; p=0.009)$ and the presence of CVD $(\mathrm{OR}=2.22 ; 95 \% \mathrm{Cl} 1.11-4.42 ; \mathrm{p}=0.024)$ were maintained in the final model, as they were significantly associated with the occurrence of periodontitis. When an interaction model was tested for the combined effect of these variables, a significant result was not observed $(\mathrm{OR}=0.59$; 95\% $\mathrm{Cl} 0.14-2.49 ; p=0.475)$.

\section{Discussion}

This study reported a prevalence of periodontitis 
among ICU in-patients and a positive relationship between the severity of periodontitis and CVD. Additionally, higher levels of IL-1 and MMP-2 were found in individuals with periodontitis, higher levels of IL- 6 were found in individuals with DM, and higher levels of IL-1 were found in individuals with CVD.

The prevalence of periodontitis in the study sample was $48.3 \%$, mostly the mild to moderate $(51.1 \%)$ and localized $(71.6 \%)$ forms. Similar data were reported by Lages et al. (13), who observed higher clinical attachment loss than PD. Periodontitis is highly prevalent with varying patterns in different populations. However, it should be noted that the criteria used to define periodontitis may influence the prevalence presented in different studies (1).

Periodontal pathogens from the sub-gingival biofilm are related to inflammatory processes that may compromise correct organ and systemic function, contributing to a rise in morbidity, mortality, and health care-associated costs $(14,15)$. Studies $(6-8)$ have reported high levels of dental biofilm and \% sites with BOP during hospitalization, which has been corroborated by our study through high PI scores (86.9\% of patients presented scores of 2 or 3 ). The lack of adequate tools for correct individual buccal hygiene, in combination with a lack of appreciation for said hygiene by some multidisciplinary ICU professionals, are the major reasons for poor buccal hygiene (15). This fact reinforces the need for buccal hygiene protocols and the inclusion of dental professionals in the ICU team.

The present study found a positive association between periodontitis case and the occurrence of CVD in the univariate and logistic regression analyses. These findings are in accordance with several previous studies

Table 2. Association between periodontitis (prevalence, severity and extension) and systemic diseases

\begin{tabular}{lccccccccc}
\hline \multirow{2}{*}{$\mathrm{N}=182$} & \multicolumn{8}{c}{ Systemic Diseases } \\
\cline { 2 - 10 } & \multicolumn{2}{c}{ Respiratory } & \multicolumn{2}{c}{ Cardiovascular } & \multicolumn{2}{c}{ Diabetes } & \multicolumn{2}{c}{ MSD } \\
\hline Periodontitis & No & Yes & No & Yes & No & Yes & No & Yes \\
\hline \multirow{2}{*}{ No } & 81 & 13 & 36 & 58 & 64 & 29 & 51 & 56 \\
& $(49.7 \%)$ & $(68.4 \%)$ & $(62.1 \%)$ & $(46.8 \%)$ & $(50.8 \%)$ & $(51.8 \%)$ & $(60 \%)$ & $(57.7 \%)$ \\
Yes & 82 & 6 & 22 & 66 & 62 & 27 & 34 & 41 \\
Total & $(50.3 \%)$ & $(31.6 \%)$ & $(37.9 \%)$ & $(53.2 \%)$ & $(49.2 \%)$ & $(48.2 \%)$ & $(40 \%)$ & $(42.3 \%)$ \\
p value & 163 & 19 & 58 & 124 & 126 & 56 & 85 & 97 \\
OR (IC & & $0.122^{\mathrm{A}}$ ) & & $0.048^{\mathrm{A}}$ & & $0.942^{\mathrm{A}}$ & $0.742^{\mathrm{A}}$ \\
& $0.46(0.17-1.26)$ & $1.86(1.08-3.52)$ & $0.98(0.52-1.83)$ & $0.78(0.43-1.63)$
\end{tabular}

Severity

$\begin{array}{lcccccccc}\text { Mild to Moderate } & 42 & 3 & 12 & 33 & 32 & 13 & 18 & 21 \\ & (51.2 \%) & (50.0 \%) & (54.5 \%) & (50.0 \%) & (52.5 \%) & (48.1 \%) & (52.9 \%) & (51.2 \%) \\ \text { Severe } & 40 & 3 & 10 & 33 & 29 & 14 & 16 & 20 \\ \text { Total } & (48.8 \%) & (50.0 \%) & (45.5 \%) & (50.0 \%) & (47.5 \%) & (51.9 \%) & (47.1 \%) & (48.8 \%) \\ \text { p value } & 82 & 6 & 22 & 66 & 61 & 27 & 34 & 41 \\ \text { OR }\left(\mathrm{IC}_{95 \%}\right) & 1.000^{\mathrm{B}} & & 0.712^{\mathrm{A}} & & 0.709^{\mathrm{A}} & 0.712^{\mathrm{A}} \\ & 1.01(0.20-5.51) & 1.20(0.46-3.16) & 1.19(0.48-2.94) & 1.20(0.46-3.16)\end{array}$

Extension

$\begin{array}{lcccccccc}\text { Localized } & 58 & 5 & 17 & 46 & 43 & 20 & 26 & 31 \\ & (70.7 \%) & (83.3 \%) & (77.3 \%) & (69.7 \%) & (70.5 \%) & (74.1 \%) & (76.4 \%) & (75.6 \%) \\ \text { Generalized } & 24 & 1 & 5 & 20 & 18 & 7 & 9 & 10 \\ & (29.3 \%) & (16.7 \%) & (22.7 \%) & (30.3 \%) & (29.5 \%) & (25.9 \%) & (23.6 \%) & (24.4 \%)\end{array}$

\begin{tabular}{|c|c|c|c|c|}
\hline Total & 82 & 66 & 61 & 41 \\
\hline$p$ value & $0.670^{\mathrm{B}}$ & $0.495^{\mathrm{A}}$ & $0.731^{\mathrm{A}}$ & $0.681^{A}$ \\
\hline $\mathrm{OR}\left(\mathrm{IC}_{95 \%}\right)$ & $0.48(0.05-4.36)$ & $1.48(0.48-4.56)$ & $0.84(0.32-2.32)$ & $0.84(0.32-2.32$ \\
\hline
\end{tabular}

Chi-square test (A) and Fisher's exact test (B). MSD = Two or more systemic diseases. The difference in the total number of individuals with periodontitis is affected by the presence of more than one systemic disease. 
$(5,10,15,16)$. However, the direction of this association has yet to been established. Although the present study design prevents the establishment of a cause-effect relation, the nature of the association between CVD and periodontitis can be further explored by applying the causality criteria such as strength of association, consistency, specificity, temporally, biological gradient, and plausibility.

Through the univariate analysis, no significant results were found between the occurrence, the severity, and the extension of periodontitis and RD and DM in the studied population. These findings for CVD were also not significant when considering the severity and the extension of periodontitis.

Thus, the present study can be considered a good starting point for future studies directed towards providing additional information of associated between periodontitis and systemic disease among ICU in-patients.

The biological plausibility for the association between systemic diseases (such as CVD, RD and diabetes) and periodontitis is due to chronic periodontitis being a buccal infection that allows bacteria (and its by-products) into the bloodstream, activating the host's inflammatory response through various mechanisms (5).

Therefore, another cornerstone of this possible association is the ability of those bacteria to invade using pro-inflammatory cytokines. The role of interleukyne-1 (IL-1) and interleukyne-6 (IL-6) in this risk association is very often reported, as both are present in the evolution of periodontitis and CVD $(16,17)$. In this way, an individual might express a hyper-responsive profile to those harmful stimuli on the periodontal and vascular endothelium. Corroborating previous findings (16-18) our study found a positive association of high levels of IL-1 between individuals with CVD and MSD, demonstrating the affinity between systemic diseases and the rise in immunological pro-inflammatory parameters.

As for the clinical periodontal parameters, CVD individuals presented a higher percentage of BOP, $\mathrm{PD} \geq 4$ $\mathrm{mm}$, and $P D \geq 6 \mathrm{~mm}$, the latter of which was also found in $\mathrm{RD}$ individuals, this shows that signs of active periodontal inflammation are present in debilitated individuals and may hypothetically contribute to worsening of general health $(15,16)$.

On the subject of RD, its cause could be the inhalation of

Table 3: Comparative analysis of clinical periodontal parameters and chronic diseases of interest $(\mathrm{n}=182)$.

\begin{tabular}{|c|c|c|c|c|c|}
\hline \multirow{2}{*}{ Systemic Diseases } & \multicolumn{5}{|c|}{ Clinical Periodontal Parameters } \\
\hline & $\begin{array}{l}\% \text { bleeding } \\
\text { on probing }\end{array}$ & $\begin{array}{l}\% \text { sites with } \\
\mathrm{PD} \geq 4 \mathrm{~mm}\end{array}$ & $\begin{array}{l}\% \text { sites with } \\
P D \geq 6 \mathrm{~mm}\end{array}$ & $\begin{array}{l}\% \text { sites with } \\
\text { CAL } \geq 3 \mathrm{~mm}\end{array}$ & $\begin{array}{l}\% \text { sites with } \\
\text { CAL } \geq 5 \mathrm{~mm}\end{array}$ \\
\hline \multicolumn{6}{|l|}{ Respiratory (RD) } \\
\hline No $(n=163)$ & $13.7 \pm 17.0$ & $16.5 \pm 18.3$ & $1.6 \pm 3.6$ & $68.7 \pm 22.3$ & $19.9 \pm 21.7$ \\
\hline Yes $(n=19)$ & $10.1 \pm 11.6$ & $12.7 \pm 15.4$ & $4.2 \pm 9.2$ & $67.1 \pm 26.8$ & $18.3 \pm 18.9$ \\
\hline $\mathrm{p}$ value & 0.237 & 0.329 & 0.023 & 0.810 & 0.732 \\
\hline \multicolumn{6}{|c|}{ Cardiovascular (CVD) } \\
\hline No $(n=58)$ & $10.1 \pm 12.2$ & $12.0 \pm 14.6$ & $2.1 \pm 5.0$ & $64.5 \pm 26.7$ & $17.1 \pm 18.3$ \\
\hline Yes $(n=124)$ & $14.8 \pm 18.0$ & $18.1 \pm 19.2$ & $4.8 \pm 10.0$ & $70.4 \pm 20.5$ & $21.0 \pm 22.6$ \\
\hline $\mathrm{p}$ value & 0.043 & 0.020 & 0.017 & 0.140 & 0.224 \\
\hline \multicolumn{6}{|l|}{ Diabetes (DM) } \\
\hline No $(n=126)$ & $13.6 \pm 16.2$ & $16.9 \pm 19.5$ & $4.4 \pm 9.7$ & $67.0 \pm 22.6$ & $18.4 \pm 21.0$ \\
\hline Yes $(n=56)$ & $12.7 \pm 17.5$ & $14.5 \pm 14.4$ & $2.9 \pm 6.3$ & $71.9 \pm 23.3$ & $22.9 \pm 22.0$ \\
\hline $\mathrm{p}$ value & 0.762 & 0.357 & 0.211 & 0.190 & 0.200 \\
\hline \multicolumn{6}{|l|}{ MSD } \\
\hline No $(n=85)$ & $13.4 \pm 16.4$ & $16.6 \pm 12.1$ & $4.2 \pm 6.8$ & $59.2 \pm 21.3$ & $19.7 \pm 19.3$ \\
\hline Yes $(n=97)$ & $14.2 \pm 11.5$ & $15.1 \pm 12.7$ & $3.9 \pm 6.2$ & $63.5 \pm 22.1$ & $21.8 \pm 21.7$ \\
\hline$p$ value & 0.563 & 0.431 & 0.277 & 0.172 & 0.384 \\
\hline
\end{tabular}

The significance probability refers to the Student's $t$ test. $\mathrm{PD}=$ probing depth; $\mathrm{CAL}=$ clinical attachment level. MSD = Two or more systemic diseases. 
bacteria into the lower respiratory tract, which is associated with the failure of the defense mechanisms to eliminate the bacteria, resulting in infection and destruction of pulmonary tissue (7). Although several studies found results similar, a previous review (5) concluded that there was not enough evidence to support the association between periodontitis and RD.

In our study, MMP-2 was found in higher levels in individuals with periodontitis, and some studies have demonstrated similar findings (19-22). However, Rai et al. (23) and Maeso et al. (24) showed opposing results, with similar levels with or without illness or even lower levels

Table 4: Comparative analysis of the presence, severity, and extension of periodontitis in relation to the levels of IL-1, IL-6, and MMP-2 $(n=182)$.

\begin{tabular}{|c|c|c|c|}
\hline \multirow{2}{*}{ Analysis Group } & \multicolumn{3}{|c|}{ Immunological Parameters } \\
\hline & IL-1 & IL-6 & MMP-2 \\
\hline \multicolumn{4}{|l|}{ Periodontitis } \\
\hline No $(n=94)$ & $67.4 \pm 72.2$ & $0.4 \pm 0.8$ & $120.6 \pm 22.2$ \\
\hline Yes $(\mathrm{n}=88)$ & $146.1 \pm 117.9$ & $0.8 \pm 2.0$ & $137.9 \pm 38.5$ \\
\hline $\mathrm{p}$ value & $<0.001$ & 0.983 & 0.025 \\
\hline \multicolumn{4}{|l|}{ Severity $(n=88)$} \\
\hline $\begin{array}{l}\text { No periodontitis } \\
(\mathrm{n}=94)\end{array}$ & $67.4 \pm 72.2$ & $0.4 \pm 0.8$ & $120.6 \pm 22.2$ \\
\hline $\begin{array}{l}\text { Mild to moderate } \\
\text { Periodontitis } \\
(\mathrm{n}=45)\end{array}$ & $121.4 \pm 103.8$ & $0.6 \pm 1.5$ & $137.2 \pm 36.7$ \\
\hline$p$ value & 0.003 & 0.310 & $<0.001$ \\
\hline $\begin{array}{l}\text { No Periodontitis } \\
(\mathrm{n}=94)\end{array}$ & $67.4 \pm 72.2$ & $0.4 \pm 0.8$ & $120.6 \pm 22.2$ \\
\hline $\begin{array}{l}\text { Severe } \\
\text { periodontitis } \\
(n=43)\end{array}$ & $174.8 \pm 129.2$ & $1.1 \pm 2.4$ & $138.7 \pm 41.5$ \\
\hline $\mathrm{p}$ value & $<0.001$ & 0.012 & $<0.001$ \\
\hline \multicolumn{4}{|l|}{ Extension $(\mathrm{n}=88)$} \\
\hline $\begin{array}{l}\text { No periodontitis } \\
(\mathrm{n}=94)\end{array}$ & $67.4 \pm 72.2$ & $0.4 \pm 0.8$ & $120.6 \pm 22.2$ \\
\hline $\begin{array}{l}\text { Localized } \\
\text { periodontitis } \\
(n=63)\end{array}$ & $127.3 \pm 99.1$ & $0.6 \pm 1.4$ & $140.9 \pm 38.3$ \\
\hline $\mathrm{p}$ value & 0.001 & 0.291 & 0.001 \\
\hline $\begin{array}{l}\text { No Periodontitis } \\
(\mathrm{n}=94)\end{array}$ & $67.4 \pm 72.2$ & $0.4 \pm 0.8$ & $120.6 \pm 22.2$ \\
\hline $\begin{array}{l}\text { Generalized } \\
\text { Periodontitis } \\
(n=25)\end{array}$ & $191.8 \pm 149.4$ & $1.3 \pm 3.0$ & $131.1 \pm 39.8$ \\
\hline $\mathrm{p}$ value & 0.001 & 0.007 & 0.049 \\
\hline
\end{tabular}

Diagnosis of periodontitis, severity and extent of periodontitis $=88$ individuals; The significance probability refers the Mann-Whitney test. in individuals with gingivitis or periodontitis. As ELISA cannot discriminate between dormant and active MMP, this may be a technical limitation, which would justify the contradictory findings as well as the need for further study.

IL-1 was shown in several studies to be a cytokine associated as much with periodontitis $(23,24)$ as with the pathogenesis of several CVDs $(16,17)$. Our results showed statistically significant differences in the levels of IL-1 in individuals with CVD and periodontitis.

In our study, levels of IL-6 found in individuals with DM and MSD were higher than in individuals without the disease, which matches the results of several studies $(19,25,26)$. Additionally, in systematic reviews, DM has been strongly associated with periodontitis $(5,6)$.

Corroborating findings from previous studies $(23,24,26)$, it is emphasized that significant associations were reported for all levels of cytokines when individuals with severe and generalized periodontitis were compared to individuals without periodontitis.

Another important finding is the positive relationship between alcoholism and periodontitis in our final logistic

Table 5. Comparative analysis between the levels of IL-1, IL-6, and MMP-2 and chronic diseases of interest $(n=182)$.

\begin{tabular}{|c|c|c|c|}
\hline \multirow{2}{*}{ Systemic Diseases } & \multicolumn{3}{|c|}{ Immunological Parameters } \\
\hline & IL-1 & IL-6 & MMP-2 \\
\hline \multicolumn{4}{|l|}{ Respiratory (RD) } \\
\hline No $(n=163)$ & $110.7 \pm 107.8$ & $0.6 \pm 1.6$ & $128.7 \pm 31.4$ \\
\hline Yes $(n=19)$ & $63.7 \pm 44.2$ & $0.1 \pm 0.1$ & $140.1 \pm 49.7$ \\
\hline $\mathrm{p}$ value & 0.444 & 0.592 & 0.668 \\
\hline \multicolumn{4}{|l|}{$\begin{array}{l}\text { Cardiovascular } \\
\text { (CVD) }\end{array}$} \\
\hline No $(n=58)$ & $71.8 \pm 67.8$ & $0.7 \pm 2.1$ & $128.1 \pm 32.8$ \\
\hline Yes $(n=124)$ & $125.1 \pm 116.0$ & $0.6 \pm 1.2$ & $130.1 \pm 32.8$ \\
\hline $\mathrm{p}$ value & 0.029 & 0.301 & 0.996 \\
\hline \multicolumn{4}{|l|}{ Diabetes (DM) } \\
\hline No $(n=126)$ & $90.4 \pm 75.3$ & $0.4 \pm 1.6$ & $128.8 \pm 34.1$ \\
\hline Yes $(n=56)$ & $150.7 \pm 151.0$ & $1.0 \pm 1.3$ & $131.0 \pm 29.4$ \\
\hline $\mathrm{p}$ value & 0.172 & 0.002 & 0.393 \\
\hline \multicolumn{4}{|l|}{ MSD } \\
\hline No $(n=85)$ & $88.5 \pm 58.9$ & $0.8 \pm 3.2$ & $131.7 \pm 33.2$ \\
\hline Yes $(n=97)$ & $127.2 \pm 121.00$ & $0.6 \pm 2.1$ & $130.6 \pm 28.9$ \\
\hline$p$ value & 0.042 & 0.003 & 0.431 \\
\hline
\end{tabular}

The significance probability refers to the Mann-Whitney test. MSD = Two or more systemic diseases. 
regression model ( $O R=2.42)$. Lages et al. (13) also reported worse periodontal health among individuals with higher alcohol intake or alcohol abuse. Alcoholism may contribute to an increase in the biofilm formation rate and its build up, since alcohol can cause buccal dehydration via a decrease in salivary flow. Moreover, alcohol may affect the host's response to bacterial infections, therefore increasing the host's vulnerability (13).

Our study has the limitations of using a convenience sample, a small sample size (despite the strict exclusion criteria), and the temporality of the study design. Thus, our findings should be interpreted with caution for external validation. In this sense, further studies with different populations and designs should be conducted for further information on the clinical and immunological periodontal condition and a possible association between periodontitis and systemic diseases of ICU individuals.
Indeed, the prevention, diagnosis, and treatment of periodontitis, aiming for periodontal health maintenance, would avoid the disabling effects of the illness, such as alveolar bone loss and tooth loss. In addition, the fact that periodontitis has been postulated, in spite of ongoing debate, as a possible risk factor for the development or recrudescence of systemic illnesses is enough to justify a bigger investment in public health and treatment of periodontitis (5).

ICUs aim to improve the odds of medical recovery for individuals in high-risk situations. Therefore, it is suggested that more concern should be raised regarding an individual's physical, mental, and psychological well-being in ICUs.

In conclusion, a prevalence of $48.3 \%$ of periodontitis has been reported in ICU in-patients, and a positive association has been observed between periodontitis and $C V D$, suggesting the potential significance of periodontal

Table 6: Logistic regression analysis to identify factors associated with periodontitis case $(\mathrm{n}=182)$.

\begin{tabular}{|c|c|c|c|c|c|}
\hline Variable & $\beta$ & $\begin{array}{c}\text { Chi-square } \\
\text { (Wald) }\end{array}$ & $p$ value & O.R. & $\begin{array}{c}\text { 95\%C.I for } \\
\text { O.R. }\end{array}$ \\
\hline \multicolumn{6}{|l|}{ Initial Model } \\
\hline Intercept & -1.020 & 4.680 & 0.030 & - & - \\
\hline Age group 40-49 years & 0.302 & 0.659 & 0.417 & 1.353 & $(0.65 ; 2.81)$ \\
\hline Periodontal disease history & 0.639 & 1.877 & 0.171 & 1.895 & $(0.76 ; 4.73)$ \\
\hline Smoker & 0.660 & 2.117 & 0.146 & 1.934 & $(0.80 ; 4.70)$ \\
\hline Former smoker & 0.438 & 1.286 & 0.257 & 1.550 & $(0.73 ; 3.31)$ \\
\hline Alcoholic & 0.728 & 4.002 & 0.045 & 2.070 & $(1.01 ; 4.22)$ \\
\hline Respiratory disease & -0.729 & 1.105 & 0.293 & 0.482 & $(0.12 ; 1.88)$ \\
\hline Cardiovascular disease & 0.536 & 1.739 & 0.187 & 1.709 & $(0.77 ; 3.79)$ \\
\hline \multicolumn{6}{|l|}{ Final Model } \\
\hline Variable & $\beta$ & $\begin{array}{c}\text { Chi-square } \\
\text { (Wald) }\end{array}$ & $p$ & O.R. & $\begin{array}{c}\text { 95\%C.I for } \\
\text { O.R. }\end{array}$ \\
\hline Intercept & -0.878 & 7.419 & 0.006 & - & - \\
\hline Alcoholic & 0.882 & 6.813 & 0.009 & 2.42 & $(1.25 ; 4.68)$ \\
\hline Cardiovascular disease & 0.797 & 5.129 & 0.024 & 2.22 & $(1.11 ; 4.42)$ \\
\hline \multicolumn{6}{|l|}{ Final Model with Interaction } \\
\hline Variable & $\beta$ & $\begin{array}{c}\text { Chi-square } \\
\text { (Wald) }\end{array}$ & $p$ & O.R. & $\begin{array}{c}\text { 95\%C.I. for } \\
\text { O.R. }\end{array}$ \\
\hline Intercept & -1.022 & 6.907 & 0.009 & - & - \\
\hline Alcoholic & 0.994 & 4.801 & 0.028 & 2.70 & $(1.11 ; 6.58)$ \\
\hline Cardiovascular disease & 1.245 & 4.120 & 0.042 & 3.47 & $(1.04 ; 11.55)$ \\
\hline Alcoholic X Cardiovascular disease & -0.524 & 0.511 & 0.475 & 0.59 & $(0.14 ; 2.49)$ \\
\hline
\end{tabular}

The p-value refers to the significance probability of test Wald for the logistic regression analysis. Initial Model - Pseudo R ${ }^{2}$ (Cox \&t Snell) $\rightarrow$ 0.127; Pseudo R ${ }^{2}$ (Nagelkerke) $\rightarrow$ 0.169. Final Model - Pseudo R ${ }^{2}$ (Cox \&t Snell) $\rightarrow 0.071$; Pseudo R ${ }^{2}$ (Nagelkerke) $\rightarrow$ 0.095; Final Model with interaction - Pseudo R ${ }^{2}$ (Cox \& Snell) $\rightarrow 0.074$; Pseudo R ${ }^{2}$ (Nagelkerke) $\rightarrow 0.099$. 
health in the prevention of harmful cardiovascular events. IL-1 and MMP-2 have been associated with the occurrence of periodontitis, IL-1 has been associated with CVD, and IL-6 has been associated with DM.

\section{Acknowledgements}

The present study was supported by grants from Conselho Nacional de Desenvolvimento Científico e Tecnológico - CNPq Brazil (CNPq \#552264/2011-3 e \#301826/2012-9). Authors revealed to have no potential conflicts of interest.

\section{Resumo}

Existem poucos estudos sobre o estado clínico periodontal e imunológico de pacientes em unidade de terapia intensiva (UTI). 0 objetivo do presente estudo foi avaliar a condição periodontal entre os pacientes internados na UTI através de parâmetros clínicos periodontais e imunológicos. De uma amostra inicial de 373 pacientes internados em UTI, 183 foram submetidos a exame periodontal completo e análise imunológica. Os dados sobre 0 sangramento na sondagem (BOP), profundidade de sondagem (PD) e nivel clínico de inserção (CAL) foram coletados e as amostras de fluido sulcular gengival foram quantificadas para avaliação imunológica através de ELISA para IL-1, IL-6 e MMP-2. Os dados foram analisados estatisticamente pelos testes de Qui-quadrado, exato de Fischer, Mann-Whitney, correlação de Sperman e análise de regressão logística multivariada. Foi observado um alto indice de placa dental e uma alta prevalência de periodontite $(48,3 \%)$, principalmente na forma crônica moderada e localizada. Os individuos com periodontite apresentaram niveis mais altos de IL-1 e MMP-2, $\cong$ enquanto indivíduos com doença cardiovascular (CVD) e com mais de duas doenças sistêmicas (MSD) apresentaram níveis mais altos de IL-1 e os com diabetes mellitus (DM) e MSD apresentaram níveis mais elevados de IL-6. Foi encontrada associação positiva entre a gravidade da periodontite e CVD (OR 2.2; IC = 1,11-4,42). Este estudo reportou uma prevalência de periodontite em $48.3 \%$ dos pacientes em UTI e uma associação positiva entre ocorrência de periodontite e CVD. Além disso, níveis mais elevados de IL-1 e MMP-2 foram encontrados em individuos com periodontite, de IL-6 em indivíduos com DM e de IL-1 em indivíduos com CVD.

\section{References}

1. Armitage GC. Development of a classification system for periodontal diseases and conditions. Ann Periodontol 1999;4:1-6.

2. Ren L, Jiang ZQ, Fu Y, Jin L. The interplay of lipopolysaccharide binding protein and cytokines in periodontal health and disease. J Clin Periodontol 2009;36:619-626.

3. Mäkelä M, Salo T, Uitto VJ, Larjava H. Matrix Metalloproteinases (MMP2 and MMP-9) of the Oral Cavity: Cellular origin and relationship to periodontal status. J Dent Res 1994;73:1397-1406.

4. Gokul K, Faizuddin, M Pradeep AR. Estimation of the level of tumor necrosis factor- $\alpha$ in gingival crevicular fluid and serum in periodontal health and disease: A biochemical study. Indian J Dent Res 2012;23:348-352.

5. Linden GJ, Lyons A, Scannapieco FA. Periodontal systemic associations: review of the evidence. J Periodontol 2013;84:S8-S19.

6. Sjögren P. Hospitalization associated with a deterioration in oral. Evid Based Dent 2011;12:48.

7. Liu Z, Zhang W, Zhang J, Zhou X, Zhang L, Song Y, Wang Z. Oral hygiene, periodontal health and chronic obstructive pulmonary disease exacerbations. J Clin Periodontol 2012;39:45-52.

8. Sachdev M, Ready D, Brealey D, Ryu J, Bercades G, Nagle J, et al., Changes in dental plaque following hospitalization in a critical care unit: an observational study. Critical Care 2013;17:R189.

9. Tomar SL, Asma S. Smoking-attributable periodontitis in the United
States: findings from NHANES III. National Health and Nutrition Examination Survey. J Periodontol 2000;71:743-751.

10. Gomes-Filho IS, Cruz SS, Rezende EJ, Dos Santos CA, Soledade KR, Magalhães $M A$, et al., Exposure measurement in the association between periodontal disease and prematurity/low birth weight. J Clin Periodontol 2007;34:957-963.

11. Silness J, Löe H. Periodontal disease in pregnancy. II. Correlation between oral hygiene and periodontal condition. Acta Odont Scan 1964;22:121-135.

12. Lorentz TCM, Cota LOM, Cortelli JR, Vargas AMD, Costa FO. Prospective study of complier individuals under periodontal maintenance therapy: Analysis of clinical periodontal parameters, risk predictors and the progression of periodontitis. J Clin Periodontol 2009;36:58-67.

13. Lages EJ, Costa FO, Cortelli SC, Cortelli JR, Cota LO, Cyrino RM, et al., Alcohol consumption and periodontitis: quantification of periodontal pathogens and cytokines. J Periodontol 2015;86:10581068.

14. Needleman I, Hyun-Ryu J, Brealey D, Sachdev M, Moskal-Fitzpatrick $D$, Bercades $G$, et al., The impact of hospitalization on dental plaque accumulation: an observational study. J Clin Periodontol 2012;39:10111016.

15. Terezakis E, Needleman I, Kumar N, Moles D, Agudo E. The impact of hospitalization on oral health: a systematic review. J Clin Periodontol 2011;38:628-636.

16. Schenkein HA, Loos BG. Inflammatory mechanisms linking periodontal diseases to cardiovascular diseases. J Periodontol 2013;84:S51-S69.

17. Ikonomidis I, Tzortzis S, Andreadou I, Paraskevaidis I, Katseli C,

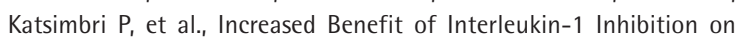
Vascular Function, Myocardial Deformation, and Twisting in Patients With Coronary Artery Disease and Coexisting Rheumatoid Arthritis. Circ Cardiovas Imaging 2014;7:619-628.

18. Tousoulis D, Oikonomou E, Economou EK, Crea F, Kaski JC. Inflammatory cytokines in atherosclerosis: current therapeutic approaches. Eur Heart J 2016;37:1723-1732.

19. Tangvarasittichai $S$, Pongthaisong $S$, Tangvarasittichai O. Tumor necrosis factor- $\alpha$, interleukin-6, C-reactive protein levels and insulin resistance associated with type 2 diabetes in abdominal obesity women. Indian J Clin Biochem 2016;31:68-74.

20. Gonçalves PF, Huang $H$, McAninley $S$, et al. Periodontal treatment reduces matrix metalloproteinase levels in localized aggressive periodontitis. J Periodontol 2013;84:1801-1808.

21. Pozo P, Valenzuela MA, Melej C, Zaldívar M, Puente J, Martínez B. et al., Longitudinal analysis of metalloproteinases, tissue inhibitors of metalloproteinases and clinical parameters in gingival crevicular fluid from periodontitis-affected patients. J Periodont Res 2005;40:99-207.

22. Pietruska M, Pietruski J, Skurska A, Bernaczyk A, Zak J, Zelazowska B et al. Assessment of aprotinin influence on periodontal clinical status and matrix metalloproteinases 1,2 and their tissue inhibitors saliva concentrations in patients with chronic periodontitis. Adv Med Sci 2009;54:239-246.

23. Rai B, Kharb $\mathrm{S}$, Jain R, Anand SC. Biomarkers of periodontitis in oral fluids. J Oral Sci 2008;50:53-56.

24. Maeso G, Bravo M, Bascones A. Levels of metalloproteinase-2 and -9 and tissue inhibitor of matrix metalloproteinase- 1 in gingival crevicular fluid of patients with periodontitis, gingivitis, and healthy gingiva. Quintessence Int 2007; 38:247-252.

25. Cardellini M, Andreozzi F, Laratta E, Marini MA, Lauro R, Hribal ML, et al., Plasma interleukin-6 levels are increased in subjects with impaired glucose tolerance but not in those with impaired fasting glucose in a cohort of Italian Caucasians. Diabetes Metab Res Rev 2007;23:141-145.

26. Cardoso EM, Reis C, Manzanares-Céspedes MC. Chronic periodontitis, inflammatory cytokines, and interrelationship with other chronic diseases. Postgrad Med 2018;30:98-104. 